\title{
Is The Children CGPA Affected By Working Mothers: Across Sectional Study Of Students In Lebanese Universities
}

\author{
Pierre Al-Khoury \\ Lebanese German University, Lebanon \\ Daoud Cheiboub Zein \\ University of Bath, UK \\ Randa Saade \\ International School of Management, France
}

\begin{abstract}
"The working mother" isn't a new concept in the global market, so is balancing between home, children and work. A misconception in the world says that the academic performance of children is negatively affected when the mother is a "working mother". However, the real scenario is different: working mothers are more sensitive to their children's education, from their academic performance, to their achievement of higher grades and CGPA. Data was collected from the Lebanese working parents and convenience sampling is used to collect data. Three-hundred respondents response is analyzed and $96 \%$ academic participation is seen. Working mothers in early infant ages of their children showed less academic performance as compared to those mothers who stayed at home in same period. Bianchi, Robinson, and Milkie (2006) demonstrated that the employed mothers are creative and finds ways to spend and maintain interactional time with their children.
\end{abstract}

Keywords: Working Mothers, Non-Working Mothers, Parents Working, Children Academic Participation, Academic Performance, GPA, CGPA

\section{INTRODUCTION \& LITERATURE REVIEW}

Primary indicators like academic performance and score achievement from graduation school (Nasir, 2012) generally assess the education quality. Besides being determinants of quality, there are many other demographic as well as social and economic factors, related to quality enhancement of the education, that need to be studied and analyzed to conclude their effect on the academic progress and the grades of the students.

The number of students graduating every year has been on increasing pace in Lebanon. So is the competition amongst the graduates in white-collar job market. One of the indicators highlighting the qualification of university students is their grades or CGPA. Employers screen out/shortlist candidates based on their academic achievements and higher CGPA.

CGPA reflects the academic performance of the student/candidate. There are many determinants related to attaining higher CGPA including gender. It is found that male and female students academic performance is not similar (Jaeger \& Eagan, 2007, Cole \& Espinoza, 2008). Age (Keith, Byerly, Floerchinger, Pence, \& Thornberg, 2009), living place, family income level(Tuttle, 2004; Davis-Kean, 2005;Yousefi, 2010), social environment, parents education (Acharya \& Joshi, 2009),standing quality, rating of graduated school, high school average grade points (GPA), and time spent on studies and learning ability also affect the performance of the students. 
Research depicts the status of mother's employment around the globe and it plays a vital role in the management of the house and the children. The non-employed and employed mothers reveal meaningful differences related to the children academic profile. The working mothers even effect differently the boys and girls, as well as the middle and lower class. The path of mother employment status and child outcome is long term and many steps are involved into it.

The children of employed and non-employed mothers shows different outcome from each other. As it is seen, the female children/daughters of working mothers attained higher academic achievement, greater career success, more non-traditional career choices, and greater occupational commitment. While the children from low-income backgrounds or single parent and mothers employed even attained higher cognitive scores. Whereas the sons of employed mothers showed lower grades and school performance, but the advanced studies reveal that there is no remarkable difference in academic performance of children (gender differentiation) whose mothers are working (Gordon, 2011).

The mother's employment was taken as a sign of inadequacy in bread winning, since both partners have to support each other in maintaining the individual tasks in the family. The daughters of working mothers have been found to be more independent, particularly in interacting with their peers in a school setting, and to score higher on socio-emotional adjustment measures. In the 1970s research, it was found that in blue collar class, the sons of working mothers showed higher levels of academic performance. The daughters of working mothers showed less acting out behavior, less shy, more independent and had a higher sense of efficacy. Whereas the boys also attained higher grades with a higher acting-out behavior than the sons of full-time homemakers did.

Children's academic performance is a communal interface combination, and an achievement of higher grades is the index determining the child's future (Ahsan \& Kumar, 2013). The competitive world is seeking for the best professionals, with higher academic profiles, as the quality becomes the core competitive indicator everywhere, putting a lot of pressure on academicians, parents, education system and students (Ahsan \& Kumar, 2013). In addition, the whole education system revolves around the student's academic achievement: It's biased upon inherent talent as well as the environmental features of an individual.

Kovacs (1999) argued that the working mother's daughters reported higher grades and academic performance. He reported opposite effects among sons/boys explaining, however, that it's due to differential effects of maternal aspirations and role moldings on girls and boys. Suneetha and Mayuri (2001)'s research showed that the boys and girls result into significantly different results in drilling, interacting and language dimensions of study habit inventory.

Academic achievement is a key indicator and criterion to judge one's total potentiality, capabilities and capacities. It's going up side in social status, and it's recognized universally as the core detriment of a person's adult status in his/her career (Ahsan \& Kumar, 2013). The mother's education affects her children's academics performance irrespective of status, social background, gender gap and other stereotype, resulting in image and pigeonhole effects. Education eradicates poverty, darkness, deficiency and dearth. This speaks a lot about the significance of studying academic achievement.

The Social Issues Research Center (2011) showed that parents, and especially mothers, spend more time with their children than the older generation used to do in the UK. They also show 
that mothers who have children under the age of four, spend around 135 minutes per day taking care of them.

McIntosh and Bauer (2006) reported that working mothers affect their children emotionally and academically. They also mentioned that from infancy to early ages of the child, the mother should not work but stay at home to strengthen the bonds with the child and help learn the values and the morals. This will help future communication between the parents and the child on a high school and university level.

\section{PROBLEM STATEMENT}

The global world, with its increasing pace, sets the trend of both parents working and now more than half of the working world has women participants in it, holding top positions and belonging to working class. Today's scenario depicts that about half of the families are headed by two working parents. Even though developing countries children settle with it and live comfortably with it as it becomes a part of the culture and the norm of developed economies, in developing nations it is generally heard that working mothers are hurting their children's development and are essentially bad for children. Are working mothers really bad for their children? The studies responded ambiguously and it isn't possible to do a real experimentation to verify and generalize the results. And while the part of traditional cultural societies still remains, we have stuck to the moralistic storyline about working mothers. This research study endeavors to find out the correlation and causation among the relationship between working mothers and their children's cumulative grade points (CGPA).

\section{OBJECTIVES OF STUDY}

This research study endeavors to find out the role of mothers employment in academic achievement and attainment of higher CGPA. It also investigates the impact of working mother on the children's university grades and how their academic performance is affected.

\section{METHODOLOGY}

This study follows the quantitative research method to collect data from the working mothers and convenience sampling technique is used to collect data from the sampling accomplices. A structured questionnaire with items measured on 5 Point Likert scale and constituted of items in pursuance to ask about the effect of working mothers on academic achievement. 350 questionnaires were distributed among the working parents employed at different managerial and non-managerial positions. Three-hundred responses were returned to the researcher. The data is then coded and analyzed on SPSS ver. 22 to calculate the correlation among the study variables.

\section{FINDINGS \& RESULTS}

The results of Table -1 depicts the number of children of working mothers. It signifies that the females having 1 child are constituted the 126 families, 90 families having 2 to 3 children, 62 families have 3 to 5 children, and only 33 families constitutes more than 5 children.

Table - 1: Children and Working Mothers Demographics

\begin{tabular}{|c|c|c|c|c|c|c|}
\hline & \multicolumn{4}{|c|}{ no.of.children } & \multirow[t]{2}{*}{ Total } \\
\hline & & 1 & $2-3$ & $3-5$ & MORE THAN 5 & \\
\hline \multirow{2}{*}{ gende } & MALE & 59 & 17 & 19 & 9 & 104 \\
\hline & FEMALE & 67 & 73 & 43 & 13 & 196 \\
\hline Total & & 126 & 90 & 62 & 22 & 300 \\
\hline
\end{tabular}

The Table - 2 depicts the age of children out of which 151 children are of the age group of 1-3 
years and 53 are more than of 10 years old. While the infants ranging from one month to one year are 32 in number and 26 children belongs to the 5-10 years group.

Ruhm (2004) reported that the working mothers in early infant ages of their children showed less academic performance as compared to those mothers who stayed at home in same period. Bianchi, Robinson, and Milkie (2006) demonstrated that the employed mothers are creative and finds ways to spend and maintains interactional time with children, often by reducing time allocated from housework to leisure, to personal time, and to sleeping time.

Buehler O Brien (2011) shows that mothers working in a part time job are better than full time job employees are, if they have young children. This is because they will have the opportunity and time to help their children learn. In addition, in their free time, they will be able to participate with their children in school activities and support them.

Table - 2: Children Age Demographics

\begin{tabular}{|c|c|c|c|c|c|c|}
\hline & \multicolumn{5}{|c|}{ Child. Age } & \multirow[t]{2}{*}{ Total } \\
\hline & $1 \mathrm{~m}-1 \mathrm{y}$ & $1 y-3 y$ & $3 y-5 y$ & $5 y-10 y$ & More than $10 y$ & \\
\hline \multirow{3}{*}{$\begin{array}{ll}\text { gender } & \text { MALE } \\
\text { Total } & \text { FEMALE }\end{array}$} & 7 & 63 & 11 & 4 & 19 & 104 \\
\hline & 25 & 88 & 27 & 22 & 34 & 196 \\
\hline & 32 & 151 & 38 & 26 & 53 & 300 \\
\hline
\end{tabular}

The table -3 shows the mothers workability impact on child's academic participation and results.

It demonstrates that the working mothers have $96 \%$ positively significant impact on children academic performance and participation. The study of Lyn Crage (2006) highlighted that the highly educated and working mothers are more sensitive to their children and puts their focus and energy along with attentive hands on care to their children. Working mothers are well known with the importance of higher grades and insights that their core responsibility to educate their children in accordance to the contemporary economic and social needs. Mother's employment status is also related to the child's results (Crage, 2006), and outcomes of children are related with mothers' sense of well-being and-parenting style (Bransford, Brown, \& Cockking, 2000).

Table - 3: Regression Weights of Work Family Balance

\begin{tabular}{|c|c|c|c|c|c|c|c|}
\hline & & & Estimate & S.E. & C.R. & $\mathrm{P}$ & Label \\
\hline MW & $<--$ & CAP & 0.96 & .23 & 0.02 & & Supported \\
\hline
\end{tabular}

\section{DISCUSSION \&CONCLUSION}

The working mothers' employment and jobs affect the infants due to associative behavioral problems. The children's disrupted behavioral problems are reported till the age of 1 year and the safer is to join job/workplace when the children reaches to 4.5 years or Grade 1 in school. Children whose mothers are full time workers, are reported to have kids with much of the disruptive behavioral problems. Whereas the part time job holder mothers children come up with less disruptive behavioral problems. This is due to better home environment as well as the mother sensitivity. Resultantly lower cognitive scores were not found in children of mothers who worked part-time during the first year of their child's life. 
Early maternal employment was found to be associated with beneficial child outcomes when it comes to families with financial challenges or as the result of being single-parent families. In those families, children of working mothers showed higher levels of achievement and lower levels of internalizing behaviors such as anxiety and depression.

The benefits of employment result in stress depletion due to financial security. New and improved learning opportunities for children who would otherwise be home with a parent who is dealing with the ongoing stress of poverty and child-rearing challenges with little external support.

Employment was associated with negative child outcomes, however, when children were from intact, middle class families that aren't in any financial risk. In those families, early full-time employment (relative to mothers who were not working outside the home) was associated with later risk for child behavioral difficulties.

It should be noted, however, that this increased risk was not the case when mothers worked full-time when their children were toddlers or preschoolers. It appears that working full-time when the child is an infant - a critical period in terms of attachment and emotional and cognitive growth - is more likely to be associated with subsequent difficulties. Data from a recent survey of parents of adolescents in the Orthodox Jewish community did not find any differences in adolescent outcomes for those mothers who reported being at-home mothers, as compared with mothers who held other professions (Cahn, 2011).

\section{References}

Kovacs, D.D. (1999). Maternal Employment and Child Outcomes: The Direct Relationships. In L.W. Hoffman \& L.M. Youngblade (Eds), Mothers at Work: Effects on Children's Well- being, 152-173.

Bransford, J., Brown, A., \& Cockking, R. (2000). How People Learn: Brain, Mind, Experience and School. National Academy Pressm. New York: Russell Sage Foundation.

Suneetha, B. and Mayuri, K., (2001), A study on age and gender differences on the factors affecting high academic achievement. J. Comm. Guid. Res., 18(2): 197-208.

Ruhm, C. (2004). Parental Employment and Child Cognitive Development. The Journal of Human Resources, 39, 155-192.

Tuttle, T. (2004) Family Background, Locality, and the Influence on SAT Scores for Indiana Class of 2000, Hoosier Briefs.

Davis-Kean (2005). The Influence Of Parent Education and Family Income On Child Achievement: The Indirect Role of Parental Expectations and The Home Environment. Journal of Family Psychology, Volume 19, Issue 2.

Kelly L. McIntosh, William Bauer (2006) Working Mothers VS Stay at Home Mothers: Impact on Children.

Crage, L. (2006). Parental education, time in paid work and time with children. British Journal of Sociology, 57(4).

Bianchi, S. M., Robinson, J. P., \& Milkie, M. A. (2006). Changing Rhythms of American Family Life.

Jaeger,A. and Eagan,Jr. (2007). Exploring The Value Of Emotional Intelligence : A Means To Improve Academic Performance. NASPA Journal, Volume 44, Issue 3.

Darnell Cole, Araceli Espinoza (2008) Examining the Academic Success of Latino Students in Science Technology Engineering and Mathematics (STEM). Journal of College Student Development, Volume 49, Issue.

Neha Acharya, Shobhna Joshi (2009) Influence of Parents' Education on Achievement Motivation of Adolescents. Indian Journal Social Science Researches Vol. 6, No. 1

Keith, P. M., Byerly, C., Floerchinger, H., Pence, E., \& Thornberg, E. (2009). Deficit and resilience perspectives on performance and campus comfort of adult students. College Student Journal.

Yousefi, F. (2010). The Effects of Family Income on Test-Anxiety and Academic Achievement among Iranian High School Students. Asian Social Science, Volume 6, Issue 6. 
The Social Issues Research Centre (2011) The Changing Face of Motherhood.

Buehler, C., O’Brien, M. (2011). Mother's Part Time Employement: Association With Mother and Family WellBeing. Journal of Family Psychology, Volume 25, Issue 6.

Rachel A. Gordon (2011) Working mothers, stay-at-home mothers, and depression risk.

Cahn, J. (2011). Adolescent children of newly-Orthodox Jewish parents: Family functioning, parenting, and community integration as correlates of adjustment. . Doctoral Dissertation, Yeshiva University Azrieli New York.

Nasir, M. (2012). Demographic characteristics as correlates of academic acheivement of university students. Academic Research International, 2(2), 400-405.

Ahsan, D. M., \& Kumar, D. A. (2013). A study of the academic achievement of children belonging to working and non-working mothers. International Journal of Education and Allied Sciences, 5(2), 19-22. 